University of Nebraska - Lincoln

DigitalCommons@University of Nebraska - Lincoln

\title{
Soil profile method for soil thermal diffusivity, conductivity and heat flux: Comparison to soil heat flux plates
}

\author{
Steven R. Evett \\ USDA-ARS, steve.evett@ars.usda.gov \\ Nurit Agam \\ USDA-ARS, nurit.agam@gmail.com \\ William P. Kustas \\ USDA-ARS, Bill.Kustas@ars.usda.gov \\ Paul D. Colaizzi \\ USDA-ARS, Paul.Colaizzi@ARS.USDA.GOV \\ Robert C. Schwartz \\ USDA-ARS, robert.schwartz@ars.usda.gov
}

Follow this and additional works at: https://digitalcommons.unl.edu/usdaarsfacpub

Evett, Steven R.; Agam, Nurit; Kustas, William P.; Colaizzi, Paul D.; and Schwartz, Robert C., "Soil profile method for soil thermal diffusivity, conductivity and heat flux: Comparison to soil heat flux plates" (2012). Publications from USDA-ARS / UNL Faculty. 1814.

https://digitalcommons.unl.edu/usdaarsfacpub/1814

This Article is brought to you for free and open access by the U.S. Department of Agriculture: Agricultural Research Service, Lincoln, Nebraska at DigitalCommons@University of Nebraska - Lincoln. It has been accepted for inclusion in Publications from USDA-ARS / UNL Faculty by an authorized administrator of DigitalCommons@University of Nebraska - Lincoln. 


\title{
Soil profile method for soil thermal diffusivity, conductivity and heat flux: Comparison to soil heat flux plates is
}

\author{
Steven R. Evett ${ }^{\mathrm{a}, *}$, Nurit Agam ${ }^{\mathrm{b}}$, William P. Kustas ${ }^{\mathrm{c}}$, Paul D. Colaizzi ${ }^{\mathrm{a}}$, Robert C. Schwartz ${ }^{\mathrm{a}}$ \\ ${ }^{a}$ USDA-ARS Conservation E Production Research Laboratory, P.O. Drawer 10, Bushland, TX 79012, USA \\ ${ }^{\mathrm{b}}$ Gilat Research Center, Agricultural Research Organization, Rural Delivery 85280, Israel \\ ' USDA-Agricultural Research Service, Hydrology \& Remote Sensing Lab, Bldg. 007, BARC-West, Beltsville, MD 20705, USA
}

\section{A R T I C L E I N F O}

\section{Article history:}

Available online 19 May 2012

\section{Keywords:}

Soil heat flux

Thermal gradient method

Heat flux plate method

Thermal conductivity

Evaporative flux

\begin{abstract}
A B S T R A C T
Diffusive heat flux at the soil surface is commonly determined as a mean value over a time period using heat flux plates buried at some depth (e.g., $5-8 \mathrm{~cm}$ ) below the surface with a correction to surface flux based on the change in heat storage during the corresponding time period in the soil layer above the plates. The change in heat storage is based on the soil temperature change in the layer over the time period and an estimate of the soil thermal heat capacity that is based on soil water content, bulk density and organic matter content. One- or multiple-layer corrections using some measure of mean soil temperature over the layer depth are common; and in some cases the soil water content has been determined, although rarely. Several problems with the heat flux plate method limit the accuracy of soil heat flux values. An alternative method is presented and this flux gradient method is compared with soil heat flux plate measurements. The method is based on periodic (e.g., half-hourly) water content and temperature sensing at multiple depths within the soil profile and a solution of the Fourier heat flux equation. A Fourier sine series is fit to the temperature at each depth and the temperature at the next depth below is simulated with a sine series solution of the differential heat flux equation using successive approximation of the best fit based on changing the thermal diffusivity value. The best fit thermal diffusivity value is converted to a thermal conductivity value using the soil heat capacity, which is based on the measured water content and bulk density. A statistical analysis of the many data resulting from repeated application of this method is applied to describe the thermal conductivity as a function of water content and bulk density. The soil heat flux between each pair of temperature measurement depths is computed using the thermal conductivity function and measured water contents. The thermal gradient method of heat flux calculation compared well to values determined using heat flux plates and calorimetric correction to the soil surface; and it provided better representation of the surface spatiotemporal variation of heat flux and more accurate heat flux values. The overall method resulted in additional important knowledge including the water content dynamics in the near-surface soil profile and a soil-specific function relating thermal conductivity to soil water content and bulk density.
\end{abstract}

Published by Elsevier Ltd.

\footnotetext{
the US Department of Agriculture (USDA) prohibits discrimination in all its programs and activities on the basis of race, color, national origin, age, disability, and where applicable, sex, marital status, familial status, parental status, religion, sexual orientation, genetic information, political beliefs, reprisal, or because all or part of an individual's income is derived from any public assistance program. (Not all prohibited bases apply to all programs.) Persons with disabilities who require alternative means for communication of program information (Braille, large print, audiotape, etc.) should contact USDA's TARGET Center at (202) 720-2600 (voice and TDD). To file a complaint of discrimination, write to USDA, Director, Office of Civil Rights, 1400 Independence Avenue, S.W., Washington, D.C. 20250-9410, or call (800) 795-3272 (voice) or (202) 720-6382 (TDD). USDA is an equal opportunity provider and employer.

* Corresponding author. Tel.: +1 806356 5775; fax: +1 8063565750.

E-mail addresses: steve.evett@ars.usda.gov (S.R. Evett), nurit.agam@gmail.com (N. Agam), bill.kustas@ars.usda.gov (W.P. Kustas), paul.colaizzi@ars.usda.gov (P.D. Colaizzi), robert.schwartz@ars.usda.gov (R.C. Schwart).
}

\section{Introduction}

Soil thermal properties are important inputs for models of soil heat and water flux; but thermal properties are prone to error when calculated from soil texture and bulk density data due to the complex effects of soil particle size, shape and packing. De Vries [1] developed a method of estimating soil thermal conductivity, $\kappa$, from soil texture, bulk density, $\rho_{b}$, and volumetric water content, $\theta$. The method, while including most important soil properties affecting $\kappa$, is limited in that it requires knowledge of parameters called shape factors that describe how the soil particles are packed together. The shape factors are specific to a given soil and perhaps pedon and must be measured. They are, in effect, fitting parameters. Harmonic analysis of diel soil surface and subsurface temperatures has been used to find the apparent soil thermal diffusivity, 
$\alpha$, in the field but has suffered from inaccuracy due to the assumption of homogeneous soil properties.

Horton et al. [2] developed a measurement method for $\alpha$ based on harmonic analysis. The method entailed fitting a Fourier series to the diel (24-hour) soil temperature measured at 1-h intervals at $0.01-\mathrm{m}$ depth followed by the prediction of temperatures at a depth, $z(0.1 \mathrm{~m})$, based on the Fourier series solution to the onedimensional heat flux problem using an assumed $\alpha$ value. The value of $\alpha$ was changed in an iterative fashion until the best fit between predicted and measured temperatures at $z$ was obtained. The best fit was considered to occur when a minimum in the sum of squared differences between predicted and measured temperatures was found (i.e., minimum sum of squared error, SSE). Poor fits with this and earlier methods are often due to the fact that field soils usually exhibit changing $\theta$ and $\rho_{b}$ with depth and time while the method assumes a homogeneous soil. Costello and Braud [3] used the same Fourier series solution and a nonlinear regression method, with diffusivity as a parameter to be fitted, for fitting the solution to temperatures measured at depths of $0.025,0.15$ and $0.3 \mathrm{~m}$.

Neither Horton et al. [2] nor Costello and Braud [3] addressed the dependency of $\alpha$ on $\theta$ or differences in $\theta$ between the different depths. Other papers have dealt with $\alpha$ in non-uniform soils but did not result in functional relationships between thermal properties and $\theta$, probably due to a paucity of depth-dependent soil $\theta$ data [4,5]. Soil water content often changes substantially with depth, time, and horizontal distance. Moreover, $\alpha$ is not a single valued function of $\theta$ and so is difficult to directly use in modeling. The ability of time domain reflectometry (TDR) to measure $\theta$ in layers as thin as $0.02 \mathrm{~m}[6,7]$ provided the basis for design of a system that simultaneously measures $\theta$ and temperatures at several depths. Evett [8] used measurements of soil temperature at several depths, coupled with TDR measurements of $\theta$ at the same depths, to find a relationship between $\kappa$ and $\theta$. He used the minimum SSE method [2] to find $\alpha$ for each soil layer between vertically adjacent measurements of water content and temperature. Using data only from days when water content in any one layer did not change appreciably, the daily value of $\alpha$ was determined and converted to $\kappa$ by multiplying by the volumetric heat capacity, itself determined from the layer $\theta$ and $\rho_{b}$. As water content changed with depth and over multiple days, a data set of coincident $\kappa$ and $\theta$ was populated and a $\kappa(\theta)$ function developed. The dependency of $\kappa$ on $\rho_{b}$ was ignored due to minor changes in $\rho_{b}$. Evett [8] did not investigate alternatives for fitting the temperature data; the relationship between quantity of data in a diurnal period and the precision of the $\kappa(\theta)$ function; nor the number of terms needed in the fitted Fourier series.

More recently, several advances in soil heat flux measurement have occurred, including the advent of heat pulse sensors (e.g. [9]). Sauer and Horton [10] provide an in depth review of methods. In a study to evaluate the degree to which heat flux measurements may be affected by evaporation that occurs beneath the soil surface, Heitman et al. [13] used heat pulse sensors to determine heat flux at three depths in a bare soil and they used microlysimeters to determine evaporation from the soil surface. They found large effects of subsurface evaporation immediately after precipitation events. Their system determined soil thermal diffusivity and calculated thermal conductivity using volumetric heat capacity based on nearby measurements of water content and an initial measurement of bulk density. It then provided soil heat flux values based on the thermal conductivity and a flux gradient equation. A calorimetric correction for heat divergence in each soil layer was made to the heat flux values. Soil surface temperature was not measured. A different approach involving numerical solution of the onedimensional thermal diffusion equation was used by Yang and Wang [11]. The method used soil temperature measurements at the soil surface and several soil depths. Through a correction mechanism, they calculated heat flux for each soil layer between sensors, without knowledge of the soil thermal conductivity, and obtained good agreement with measurements made using heat flux plates.

In the present study we revisit the method of Evett [8] to determine a soil thermal conductivity function in a study of the spatial and temporal variation of soil heat flux across the interrow of cotton planted in north-south rows. We then compute heat flux from the surface to $0.02-\mathrm{m}$ depth using the flux gradient method with measured soil temperatures, including the surface temperature, and thermal conductivity and volumetric heat capacity based on measured soil water content and bulk density (gradient based heat flux values are corrected for heat divergence in the layer). Heat flux values from the flux gradient method are then compared with those determined using heat flux plates and calorimetric correction to the soil surface.

\subsection{Theory}

The thermal conductivity, $\kappa\left(\mathrm{J} \mathrm{s}^{-1} \mathrm{~m}^{-1} \mathrm{~K}^{-1}\right)$, is a single-valued function of water content at any value of $\rho_{b}$ and is related to the diffusivity, $\alpha\left(\mathrm{m}^{2} \mathrm{~s}^{-1}\right)$, by:

$\kappa=\alpha C_{V}$

where the volumetric heat capacity, $C_{V}\left(\mathrm{~J} \mathrm{~m}^{-3} \mathrm{~K}^{-1}\right)$, can be calculated with reasonable accuracy from the volumetric water content, $\theta\left(\mathrm{m}^{3} \mathrm{~m}^{-3}\right)$, and the soil bulk density, $\rho_{b}\left(\mathrm{Mg} \mathrm{m}^{-3}\right)$, by:

$C_{V}=2.01 \times 10^{6} \rho_{b} / 2.65+4.19 \times 10^{6} \theta$

for a mineral soil with particle density of $2.65 \mathrm{Mg} \mathrm{m}^{-3}$ and with negligible organic matter. Development of a $\kappa$ vs. $\theta$ relationship using data from the harmonic method entails twice using averaged water contents over the depth range between temperature measurements, once to calculate $C_{V}$ and again to establish the $\kappa(\theta)$ relationship.

Heat conduction in one dimension is described by a diffusion equation:

$C_{V} \frac{\partial T}{\partial t}=\kappa \frac{\partial}{\partial z}\left[\frac{\partial T}{\partial z}\right]$

where $C_{V}$ and $\kappa$ are assumed constant in space and time; and vertical distance is denoted by $z$, time by $t$, and temperature by $T$. Note that $\kappa$ and $C_{V}$ are outside the derivatives in Eq. (3), indicating that both are constant. This is valid if neither $\theta$ nor $\rho_{b}$ change appreciably, which could often be the case for a single layer of soil during a 24-h period.

The one dimensional soil heat flux, $G$, for a homogeneous medium is described as:

$G=-\kappa \partial T / \partial z$

This is Fourier's law of heat conduction for constant conductivity. A finite difference form of Eq. (4) is the temperature gradient method:

$G=-\kappa \Delta T / \Delta z+\Delta G_{z 1 \_z 2}$

where $\Delta T$ is the temperature gradient between two depths, $\Delta z$ is the difference in depths, and $\Delta G_{z 1} z 2$ is the divergence of heat into the soil layer between the two depths. Calculation of the divergence of heat is termed a calorimetric correction and is necessary when estimating $G$ at the soil surface $\left(G_{0}\right)$ from measurements of soil heat flux at depth $z\left(G_{z}\right)$ made using heat flux plates:

$G_{0}=G_{z}+\Delta G_{0 \_}$

In this combination equation, the divergence is typically calculated using the soil temperature change between the heat flux plate and 
the soil surface during the period over which the heat flux was measured, combined with an estimate of $C_{v}$. The correction involves measuring the temperature, $T(\mathrm{~K})$, and $\theta$ at midlayer depths, $z_{j}$, in $N$ layers ( $j$ to $N$ ) between the plate and surface; and applying the combination equation over some time period, $\tau_{t}$, defined by beginning and ending times $t_{i}$ and $t_{i+1}$

$G_{0}=G_{z}+\frac{\sum_{j=1}^{N}\left(T_{z j \_i+1}-T_{z j \_i}\right) \Delta z_{j} C_{z j}}{\left(t_{i+1}-t_{i}\right)}$

where $G_{0}$ is the surface heat flux during $\tau_{t} ; G_{z}$ is the flux at depth $z$; the $T_{z j}$ are temperatures at the $N$ depths, $z_{j}$, at times $t_{i}\left(T_{z j \_}\right)$and $t_{i+1}$ $\left(T_{z j \_i+1}\right) ; \Delta z_{j}$ is the depth of the layer with midpoint $z_{j}$; and where the volumetric heat capacities, $C_{z j}$, at depths $z_{j}$ are calculated from Eq. (2), re-written as

$C_{z j}=\frac{2.0 \times 10^{6} \rho_{b z j}}{2.65}+4.2 \times 10^{6} \theta_{v z j}+2.5 \times 10^{6} f_{o z j}$

where $\theta_{v z j}, \rho_{b z j}$, and $f_{o z j}$ are the water contents, soil bulk densities, and volume fractions of organic matter, respectively, at depths $z_{j}$. Evett et al. [12] reported that the estimate of $G_{0}$ was not much changed by using two soil layers in Eq. (7) (i.e. $N=2$ ). In general, however, for situations where $\theta, T, \rho_{b}$ or $f_{\mathrm{o}}$ change rapidly with depth, the multiple layer approach will be more accurate.

If one of the depths chosen in the computation of $G$ using Eq. (5) is at the surface $(z=0)$ then the surface heat flux is estimated. However, Heitman et al. [13] showed that this calculation may overestimate the heat flux as it is considered in the surface energy balance equation:

$0=L E+G_{0}+H+R_{n}$

where $L E$ is latent energy of evaporation from the soil, $H$ is sensible heat flux from the soil to the atmosphere and $R_{n}$ is net radiation at the soil surface (all taken as positive towards the surface and in $\mathrm{W} \mathrm{m}^{-2}$ ). The reason is that evaporation occurs not just at the soil surface but in a zone beneath the surface. The depth of that zone varies with time according to the depth of the drying front. Because latent energy is being lost from the zone, the soil heat flux calculated by finite difference from the surface to depth $z$ may include energy that is converted to $L E$, resulting in a double accounting of energy flux. Essentially, the divergence of heat flux results in both soil temperature change and in latent heat flux, but Eq. (7) accounts only for soil temperature change.

A solution to Eq. (4) is given by a Fourier series with $M$ terms:

$$
\begin{aligned}
T(z, t)= & T_{m}+\sum_{n=1}^{M}\left\{C_{0 n} \exp \left[-z(0.5 n \omega / \alpha)^{0.5}\right]\right. \\
& \left.\sin \left[n \omega t+\phi_{0 n}-z(0.5 n \omega / \alpha)^{0.5}\right]\right\}
\end{aligned}
$$

where $T_{m}$ is the mean temperature (assumed the same at all depths), and the frequency $\omega$ is given in radians per unit time by $\omega=2 \pi / p$ where $p$ is the period. The amplitude, $C_{0 n}(\mathrm{~K})$, and the phase angle, $\varphi_{0 n}$ (radians), will be re-defined below. For $z=0$ (not necessarily the soil surface), Eq. (10) reduces to:

$T(0, t)=T_{m}+\sum_{n=1}^{M} C_{0 n} \sin \left(n \omega t+\phi_{0 n}\right)$

which is the upper boundary condition for the solution. The lower boundary condition is:

$T(\infty, t)=T_{m}$

Eq. (11) is equivalent to:

$T(0, t)=T_{m}+\sum_{n=1}^{M}\left[A_{0 n} \sin (n \omega t)+B_{0 n} \cos (n \omega t)\right]$ where $A_{0 n}$ and $B_{0 n}$ are the amplitudes $(K)$ of the sine and cosine terms, respectively. The phase angle and amplitude terms of Eq. (11) are related to $A_{0 n}$ and $B_{0 n}$ by $\varphi_{0 n}=\tan ^{-1}\left(B_{0 n} / A_{0 n}\right)$ and $C_{0 n}=A_{0 n} / \sin \left(\varphi_{0 n}\right)$.

Essentially, the method employed by Horton et al. [2] and Evett [8] was to fit Eq. (11) or Eq. (13) to temperature at one depth and then use the fitted coefficients and Eq. (10) to predict temperatures at another depth while varying the value of diffusivity until the SSE for the prediction was minimized. Alternatively, a nonlinear fit may be obtained using the Levenberg-Marquardt method [14], among others. However, most nonlinear fitting methods require an initial guess somewhere in the neighborhood of the best fit parameter value in order to function efficiently or, in some cases, even to converge on the correct solution. A good initial guess for the thermal diffusivity of a soil layer may be obtained from the relative amplitudes of the diurnal temperature waves at the two depths defining the layer top $\left(z_{0}\right)$ and bottom $(z)$. If the temperatures are well described by a single term in Eq. (10) then

$\boldsymbol{\alpha}=(\boldsymbol{\pi} / p)\left[-z / \ln \left(A_{M} / A_{B}\right)\right]^{2}$

where $A_{B}$ is the amplitude at $z_{0}$ and $A_{M}$ is the amplitude at $z$.

De Vries [1] and others have recognized that $\kappa$ is related to not only $\theta$ but to the soil bulk density, $\rho_{b}$, i.e. $\kappa\left(\theta, \rho_{b}\right)$. The $\kappa\left(\theta, \rho_{b}\right)$ relationship can be modeled using the equation of McInnes as given in [15]:

$\kappa=a+b \theta-\left(a-0.03-0.1 \rho_{b}^{2}\right) \exp \left[-(c \theta)^{e}\right]$

where $a, b, c$ and $e$ are fitting coefficients, $\rho_{b}$ is the soil bulk density $\left(\mathrm{Mg} \mathrm{m}^{-3}\right)$, and McInnes' fitting coefficient $d$ is taken equal to $0.03+0.1 \rho_{b}^{2}$.

In previous work [8], we used time domain reflectometry (TDR) to measure water content and thermocouples to measure corresponding temperatures at seven soil depths at each of four sites over several weeks in the Pullman soil at Bushland, TX. These TDR-temperature arrays provided data for harmonic analysis of soil thermal diffusivity and conductivity by layer. The depth-variable soil water content allowed volumetric heat capacities and thermal conductivities to be calculated for a range of water contents leading to a presentation of thermal conductivity as a function of water content as: $\kappa=-0.07+3.31(\theta), \quad r^{2}=0.9$. This relationship compared well with published data and resulted in improved calculation of $G$ by the ENWATBAL model [16], but there were no soil heat flux data from plates against which to compare the soil heat flux results from the harmonic analysis. In the present study we investigate soil heat flux in the interrow between cotton rows oriented north-south with $76-\mathrm{cm}$ row spacing, using both a thermal gradient method and soil heat flux plates.

The objectives of this study were several: (1) Develop a $\kappa\left(\theta, \rho_{b}\right)$ relationship using the method of Evett [8], fitting the data to Eq. (15); (2) Compare values of $G_{0}$ computed using the temperature gradient method (Eq. (5)) between the surface and a depth $z=0.02 \mathrm{~m}$ with those determined using soil heat flux plates buried at $0.08 \mathrm{~m}$ depth coupled with calorimetric correction to the surface; (3) Compare $G_{0}$ with the latent energy (LE) of evaporation from the soil surface as measured using microlysimeters by Agam et al. [17]; and (4) assess the temporal and spatial variation of $G_{0}$. Although it may be important, we do not in this article attempt to determine the depth range within which evaporative heat demand may be an important contributor to the measured $G_{0}$, leaving that for a separate study.

\section{Methods}

Measurements were made from 24 June to 24 September 2008 (day of year 176 to 268) in the northeast (NE) large weighing 


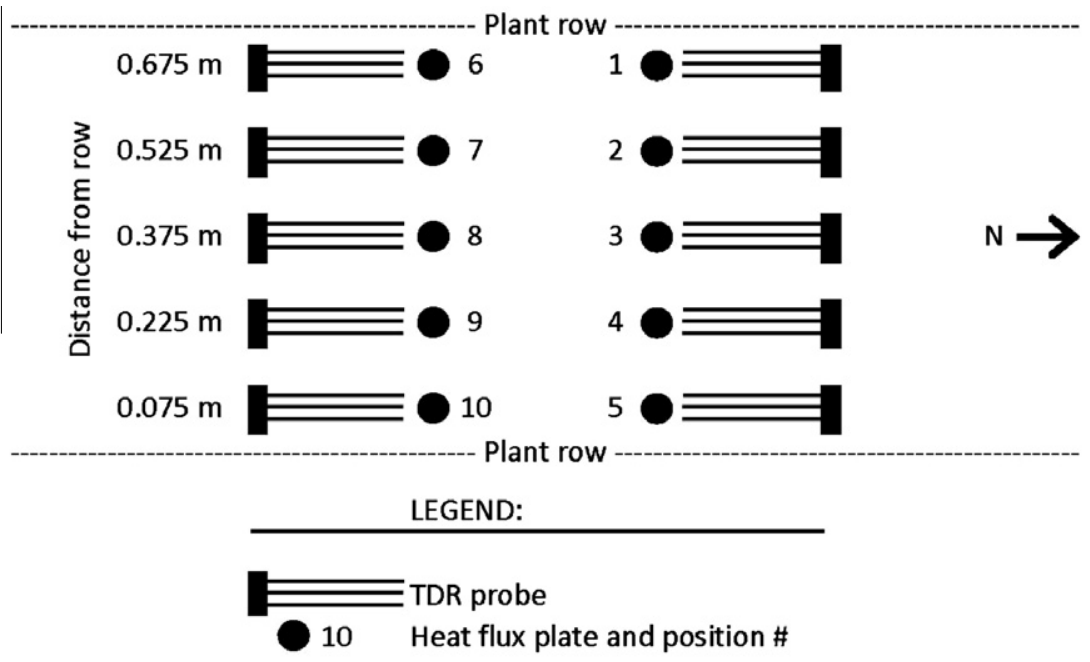

Fig. 1. Bird's eye view diagram of TDR probe and heat flux plate sensor placement, numbered by position.

lysimeter field at the USDA-ARS Conservation \& Production Research Laboratory. The field was planted to cotton and irrigated as described by Evett et al. [18]. The soil is a Pullman series silty clay loam (fine, mixed, superactive, thermic Torrertic Paleustoll). Thermocouples, time domain reflectometry (TDR) probes and soil heat flux plates were installed at ten locations for simultaneous determination of temperature, soil water content and soil heat flux (Figs. 1 and 2) at a site $30-\mathrm{m} \mathrm{NE}$ of the lysimeter. Locations were spaced across the interrow in $0.15-\mathrm{m}$ horizontal increments at two adjacent sites with five sensor locations each to allow study of sun angle effects on soil temperature and heat flux. At each location, a soil heat flux plate (model HFT-3.1 heat flow transducer ${ }^{1}$, Radiation and Energy Balance Systems, Inc. Bellevue, WA) was installed at $0.08-\mathrm{m}$ depth with copper-constantan thermocouples installed at 0, 0.02 and 0.06-m depths above it. Also at each location, trifilar TDR probes were installed horizontally at depths of 0.02 , 0.06 , and $0.12 \mathrm{~m}$ with copper-constantan thermocouples at $0,0.04$, 0.08 and $0.16 \mathrm{~m}$ depths. The TDR waveforms were automatically digitized and recorded at 0.25 - $\mathrm{h}$ intervals using an embedded computer running DOS and the TACQ program for TDR system control, data acquisition and waveform interpretation [19,20]. A TDR instrument (model 1502C, Tektronix Inc., Redmond, OR) provided the TDR waveform output. A 16-channel multiplexer with 50-ohm characteristic impedance was designed to switch the TDR signals among probes while introducing minimal signal distortion [21]. Digital signals were provided through the computer's parallel port for switching the multiplexer.

A three-wire TDR probe configuration is semi-coaxial in nature and eliminates the need for an impedance matching transformer (balun) used with a two-wire design [22]. Also, the range of sensitivity above and below the plane of the rods is narrower for the 3 wire configuration than for the 2 wire configuration most commonly used in the past [6,7] allowing for better discrimination of soil water content with depth. The three-wire TDR probes used here were shop built and consisted of an epoxy resin and polymethylmethacrylate handle from which extended three parallel, type 316 stainless steel rods. The rods were spaced in a single plane at $0.03 \mathrm{~m}$ center to center and were $0.0032 \mathrm{~m}$ (nominal $1 / 8 \mathrm{inch}$ ) in diameter and $0.2 \mathrm{~m}$ long from the tip to the point of emergence from the handle. The outer two rods were

\footnotetext{
${ }^{1}$ Mention of trade names or commercial products in this article is solely for the purpose of providing specific information and does not imply recommendation or endorsement by the U.S. Department of Agriculture.
}

soldered to the outer conductor of a type RG/6 coaxial cable and the inner rod was soldered to the inner conductor. The solder joints, proximal ends of the rods and distal end of the cable were encapsulated together in the handle, effectively waterproofing the connections. The length of rod in the handle was $0.014 \mathrm{~m}$. The physical arrangement of connections between cable and rods and the length of rods within the handle were identical in all probes to provide a reproducible TDR waveform shape among all probes. The probes were inserted into the soil from the side of a pit. A jig was used to ensure correct depth of all sensors; and to ensure that the plane of the TDR probe rods was parallel to the soil surface. The pit was backfilled with soil to approximate field bulk density and leveled. The TDR calibration in travel time, effective frequency and bulk electrical conductivity reported by Evett et al. [23] was used to minimize effects of soil bulk electrical conductivity and temperature on estimated water content. Water content data were collected from day of year (DOY) 176 to 301,2008 .

The type $\mathrm{T}$ thermocouples were purpose built by stripping the wires, twisting them tightly together, soldering the twist for mechanical reinforcement, dipping the twist in water-resistant epoxy resin and then covering the ensemble with heat shrinkable tubing. Surface thermocouples were additionally dipped in epoxy resin, which was then covered in dry soil to approximate the albedo of the surface. Thermocouples at the soil surface were held in place with white plastic zip ties wrapped around the thermocouple, tightened, cut at an angle to form a $7-\mathrm{cm}$ pointed pin and then pressed into the soil at an angle, pinning the sensor to the surface. This method of construction and installation was found to provide soil surface temperature data that were equivalent to those observed using a calibrated infrared thermometer for non-contact temperature measurement. All thermocouple extension wires were buried at $10 \mathrm{~cm}$ between the thermocouple location and the datalogger (model CR3000, Campbell Scientific Inc., Logan, UT). Temperature data were collected from DOY 176 to 268.

A computer program was written to find the coefficients of Eq. (13) using general linear least squares regression and user-chosen $M$. The data used for each regression fit were referred to as the "basis" temperatures at depth $z_{0}$. The program source (BASIC) and executable code and documentation are available at http:// www.cprl.ars.usda.gov/swmru-software.php. The fitted values of $A_{0 n}$ and $B_{0 n}$ were converted to $\varphi_{0 n}$ and $C_{0 n}$; and Eq. (10) was fit to the temperatures measured at a depth, $z$, below the depth of 

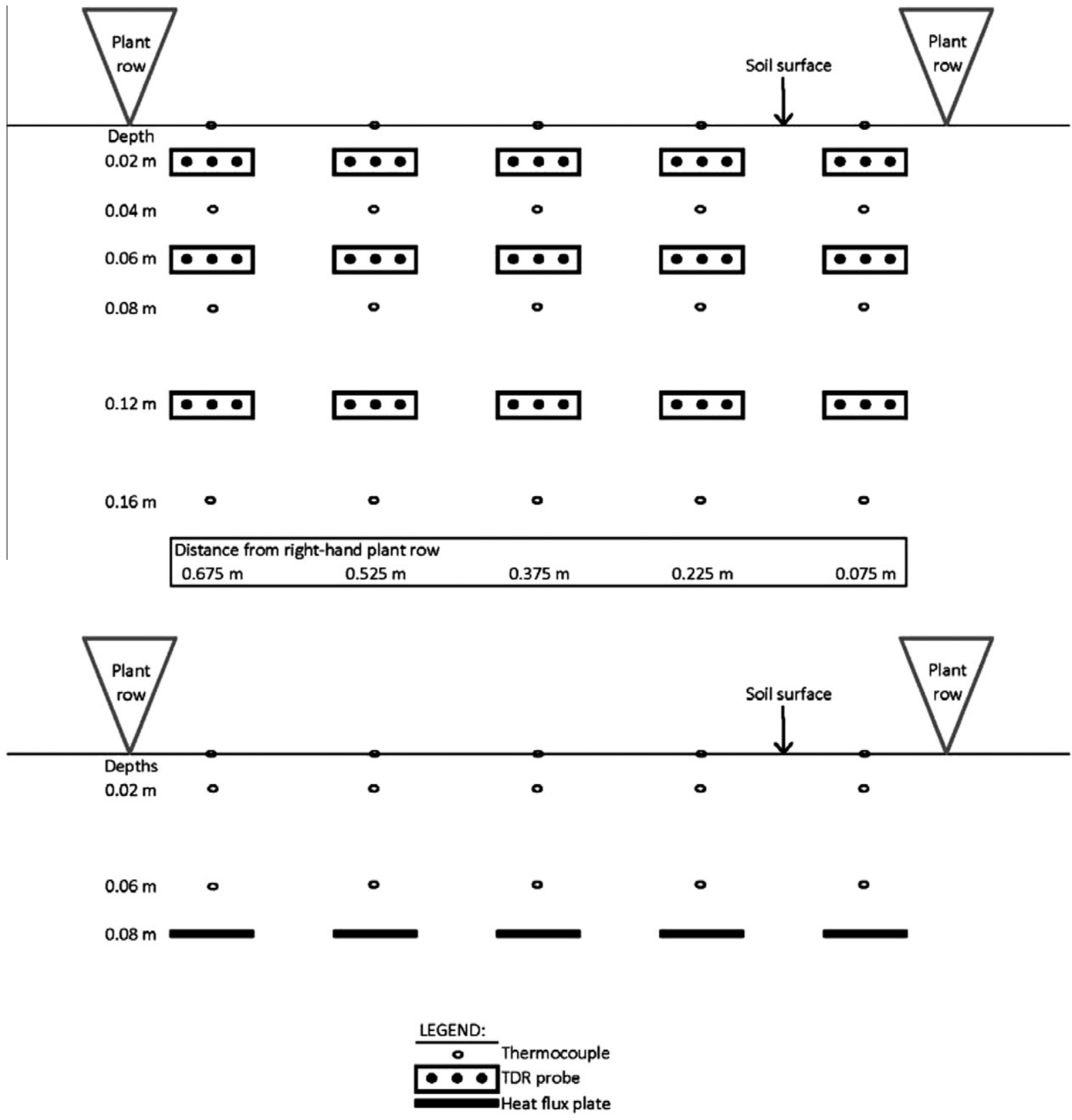

Fig. 2. Side view of sensor locations with respect to the plant rows and depths of TDR probes, thermocouples and soil heat flux plates.

measurement of the basis temperatures, using an initial estimate of $\alpha$ as calculated from Eq. (14). A Levenberg-Marquardt nonlinear least squares regression procedure [14] was used to determine the best-fit value of $\alpha$, which was the sole fitted parameter. Temperatures at the depth $z$ were called the "matching" temperatures. The mean temperature at $z$ was used as the value for the parameter $T_{M}$ in Eq. (10) rather than the value of $T_{M}$ from the fit of Eq. (13) to the basis temperatures. This procedure assumes homogeneity of soil properties in the layer between basis and matching depths. Although our data show that water content and bulk density change with depth, we justify this by noting that the discretization provided by measurement depths is appropriate given the rate of change of these important soil properties affecting the thermal conductivity. The first soil layer beneath the surface was only $4 \mathrm{~cm}$ thick, the next was $4 \mathrm{~cm}$ thick, and the third was $8 \mathrm{~cm}$ thick. Water content varies with depth most rapidly near the surface as does the bulk density. Below $8 \mathrm{~cm}$ the rate of change with depth of both properties is relatively small. Further justification lies in the computational efficiency of the method.

The position of $z_{0}$ need not be taken as the soil surface. In this study $z_{0}$ was successively set to zero for temperatures measured at depths of $0,0.04$ and $0.08 \mathrm{~m}$ (the basis temperatures) and the respective temperatures at depths of $0.04,0.08$ and $0.16 \mathrm{~m}$ were used as the matching temperatures. The diffusivity value from the fit of Eq. (10) was converted to a value of thermal conductivity by dividing by $C_{V}$, which was calculated using Eq. (8). In calculating $C_{V}$, water content for the layer between basis and matching temperatures was taken as the mean daily $\theta$ measured in that layer. Bulk density for a layer was linearly interpolated for the layer midpoint depth from a table of bulk density vs. depth.

On any given day, the Fourier series was fit to the basis temperatures from midnight to midnight. The time passing while heat propagates from one depth to another is the phase difference, PD (days), which is represented in radians by the term $z(0.5 n \omega / \alpha)^{1 / 2}$ 
in Eq. (10). Since the angular frequency $\omega$ has units of radians $d^{-1}$, factoring the angular value by the quantity $(t / 2 \pi)$, where $t=1$ day (i.e. $2 \pi$ radians in $24 \mathrm{~h}$ ), gives the phase difference, PD (days). Temperature changes beginning at midnight at the basis depth only begin to be reflected by measureable changes in temperatures at the matching depth at a time PD after midnight. Therefore, estimated temperatures at the matching depth were fit for the period from midnight plus PD on the day in question to midnight plus PD on the following day. Since the soil was either heating or cooling on many days, the 24-h temperature data usually did not start and stop at the same value. A Fourier series is constrained to return to the same value at the end of each period ( $1 \mathrm{~d})$, so there is sometimes a poor match between predicted and measured temperatures at the beginning and ending of the period. For our data, using a six-term series restricted the poor fit to within $2 \mathrm{~h}$ of the beginning and ending of the period. Therefore, the nonlinear fits to find $\alpha$ were restricted to the period from midnight $+P D+2 / 24$ on the given day to midnight $+\mathrm{PD}-2 / 24$ on the next day. Finally, since heating or cooling of the soil implies that daily mean temperature will vary with depth, the mean temperature in Eq. (10) was taken as the mean of measured values at the matching depth for the period rather than the mean at the basis depth.

The $\kappa\left(\theta, \rho_{b}\right)$ relationship was modeled using Eq. (15). Data were screened to avoid errors in $\alpha$ determination due to non-compliance with the assumptions inherent in the theory applied in this study. Because irrigation and precipitation events cause large changes in $\theta$, the assumption of constant $\theta$ is violated, in addition to which infiltration of water results in convective heat flux that is not accounted for in the theory presented. Also, large changes in soil temperature from the beginning of a 24-h period to the end of that period cause problems with fitting the sine series and establishing correct estimates of $\alpha$. For these reasons, data were omitted for days during which irrigation and precipitation occurred or during which large changes in soil temperature occurred. Fitted $\alpha$ data were also screened according to the goodness of fit, with data for which SSE was larger than a set value $(0.1)$ being omitted from the database of $\alpha$ values. Despite these screening criteria, using data from the entire season resulted in adequate data (109 data, which was $6 \%$ of all possible data) for fitting of Eq. (15).

Once the $\kappa\left(\theta, \rho_{b}\right)$ relationship was established, flux gradient soil heat flux at the surface was computed on half-hourly intervals using Eq. (5) with the measured soil surface temperatures as the upper boundary condition, the value of $C_{V}$ determined using
Eq. (2), the $\theta$ value at 2-cm depth from the TDR system, the value of $\kappa$ at $\theta$ and $\rho_{b}$, and with the soil temperatures measured at depth $z=2 \mathrm{~cm}$ as the lower boundary condition. Soil heat flux plate data were thermometrically corrected to the surface using Eq. (7), $N=2$, temperatures measured at 2- and 6- $\mathrm{cm}$ depths above each heat flux plate, and $C_{V}$ for each soil layer calculated using Eq. (8) and soil water contents measured by the TDR system at 2 - and $6-\mathrm{cm}$ depths.

Evaporation $[E]$ was measured on eight days and nights between DOY 198 and 215 using 10 microlysimeters (MLs) [17]. The MLs were made of $8-\mathrm{mm}$ thick rigid white polyvinyl chloride (PVC) tubes with 105-mm inside diameter, 88-mm depth and metal bottoms. The low thermal conductivity and white color of the plastic wall material minimizes heat conduction by the walls; and the metal bottoms avoid impedance of vertical heat transfer, design features that improve ML accuracy [26]. Soil cores were acquired using a slide hammer to drive the PVC cylinders into the soil, resulting in undisturbed cores; and these were replaced daily immediately after weighing at sunset. In each of two replicates, five MLs each were installed level with the soil surface along a cross section of the interrow at distances from the row center of $0.075,0.225,0.375,0.525$, and $0.675 \mathrm{~m}$ from west to east. Microlysimeters were installed three rows east of the heat flux measurement site and in the field in which rows were oriented north-south. To obtain daytime and nighttime $E$, the MLs were weighed at sunrise $(\sim 07: 00)$ and sunset ( 21:00) using an electronic scale with a precision of $0.1 \mathrm{~g}$ (equivalent to $0.01 \mathrm{~mm}$ water). The scale was enclosed in a covered box to avoid wind effects on the measurements. For DOY 213 and 215, the MLs were weighed every two hours from sunrise to sunset.

Similar to Agam et al. [24], heat flux data are presented for three sub-periods representing the beginning (BEG), middle (MID), and end (END) of the growing season. Sub-periods were defined based on plant height and width, and fractional vegetation cover, $f_{c}$ (see Fig. 2 in [24]). The days of year (DOY) representing the sub-periods were BEG: 181-184, 186-189, 193-194; MID: 205-206, 208-209, 211, 213, 215, 217, 219, 222; END: 239-241, 244-245, 248-251, 254. During the BEG period average $f_{c} \sim 0.25$ and plant height, $h_{c}$, $<0.4 \mathrm{~m}$, for the MID period average $f_{c} \sim 0.6$ and $0.5<h_{c}<0.7 \mathrm{~m}$, and during the END period average $f_{c} \sim 1$ and $0.9<h_{c}<1.0 \mathrm{~m}$. For purposes of comparison, an "average" day was computed for each sub-period by averaging $G_{0}$ data from the days in the sub-period at each measurement interval (15-min) during the 24 -h period from

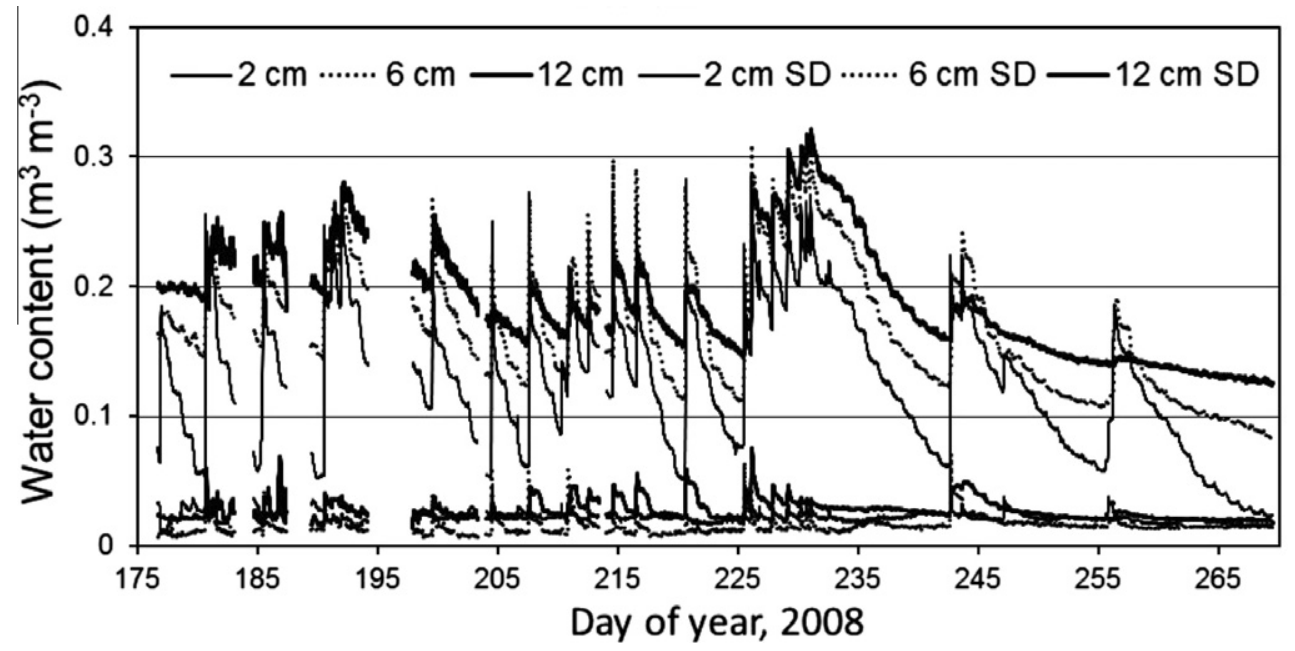

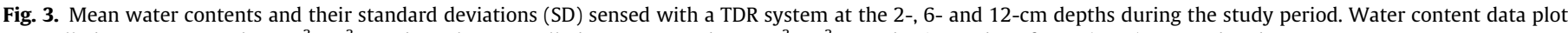
generally between 0.1 and $0.3 \mathrm{~m}^{3} \mathrm{~m}^{-3}$; SD data plot generally between 0 and $0.05 \mathrm{~m}^{3} \mathrm{~m}^{-3}$. Data begin on day of year (DOY) 176 and end on DOY 301 . 

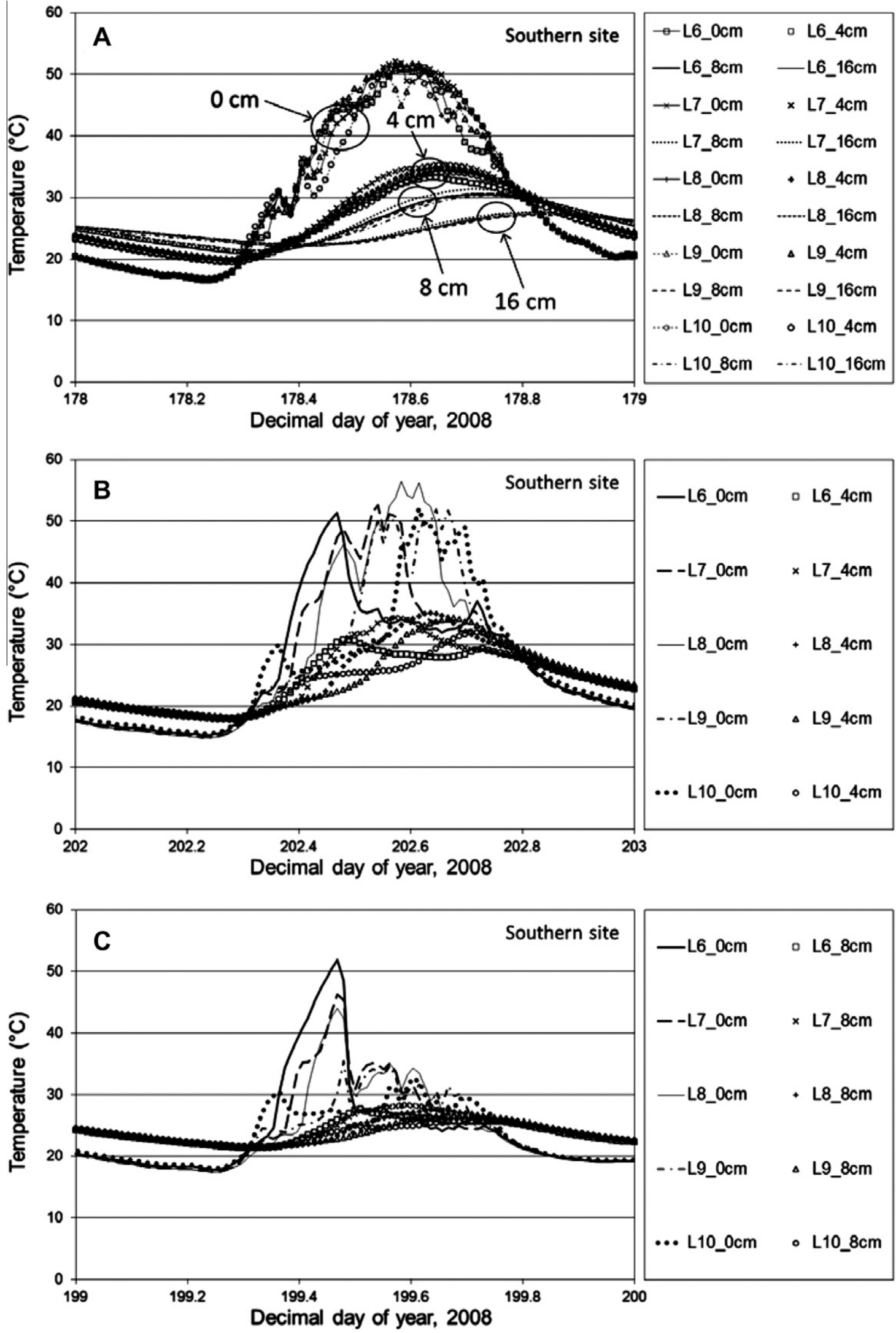

Fig. 4. Examples of temperatures at the five measurement locations on the southern side of the site (locations 6-10, shown in Fig. 1): (A) on a day early in the cropping season under relatively clear skies and with leaf area index (LAI) of $\sim 0.1$; (B) later in the season on a relatively clear day but with LAI of $\sim 0.4$, and plant height of $\sim 0.4 \mathrm{~m}$; (C) for an irrigation on day of year 199, 2008. 
midnight to midnight. Data from soil heat flux plates corrected to the surface calorimetrically (Eq. (7)) are denoted by $G_{\mathrm{PS}}$, while those from the temperature gradient method (Eq. (5)) are denoted by $G_{\text {grad. }}$.

\section{Results and discussion}

Over the entire study period, soil water content changed abruptly with irrigation and precipitation events, with the largest changes at the 2-cm depth and the smallest changes at the 12$\mathrm{cm}$ depth; during much of the study period, diel changes in water content were $>0.05 \mathrm{~m}^{3} \mathrm{~m}^{-3}$ due to frequent irrigations (Fig. 3). Standard deviations (SD) for the ten TDR probes at each depth were routinely $<0.03 \mathrm{~m}^{3} \mathrm{~m}^{-3}$, but increased to as great as $0.07 \mathrm{~m}^{3} \mathrm{~m}^{-3}$ during irrigation and precipitation events. During the periods chosen for Fourier analysis, water content was relatively stable over time but values were different by location.

Early in the season, soil temperatures were roughly sinusoidal at the surface during the relatively clear day of year 178 (Fig. 4(a)), and were damped to more clearly sinusoidal forms below the surface. The amplitudes diminished and time of peak temperature was delayed as depth increased, congruent with theory. Diel temperature variations were not sinusoidal at the surface on most days after the crop reached $0.2-\mathrm{m}$ height. For example, on DOY 202 (leaf area index of 0.43 and plant height of 0.4 ) the soil surface at locations in the western-most side of the interrow warmed first during the day, then cooled as locations progressively closer to the eastern-most side of the interrow warmed in sequence, then cooled (Fig. 4(b)). The eastern-most locations in
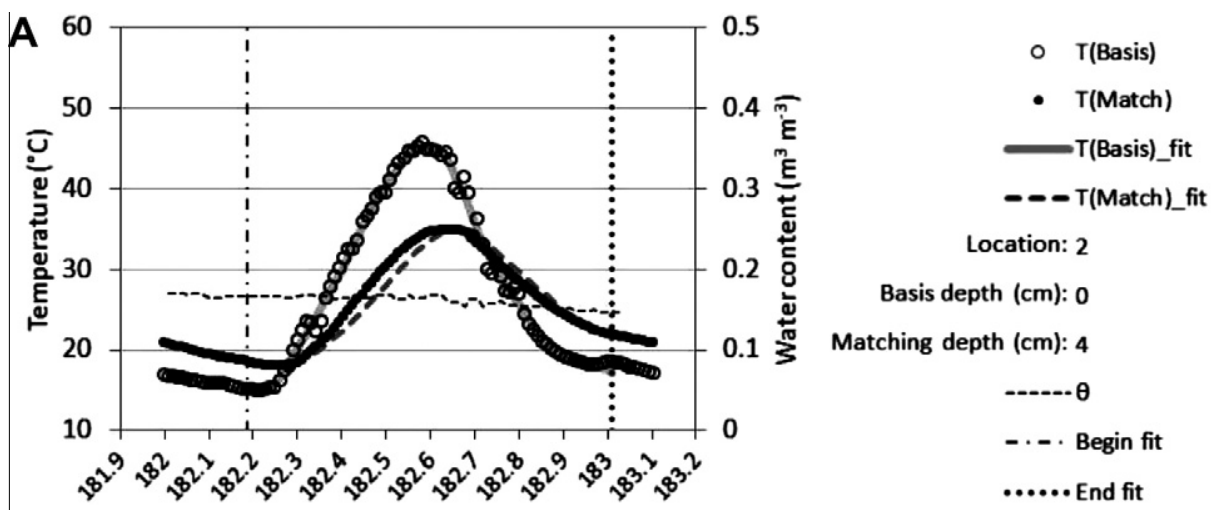

Location: 2

Basis depth $(\mathrm{cm}): 0$

Matching depth $(\mathrm{cm}): 4$

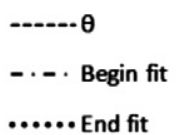

B 60



0.5

$0.4 \underset{\text { m }}{m}$

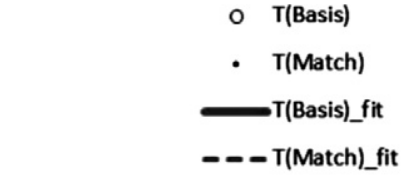

Location: 6

Basis depth $(\mathrm{cm}): 0$

Matching depth $(\mathrm{cm}): \mathbf{4}$

-----.-vwc

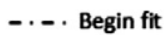

....... End fit

C 60

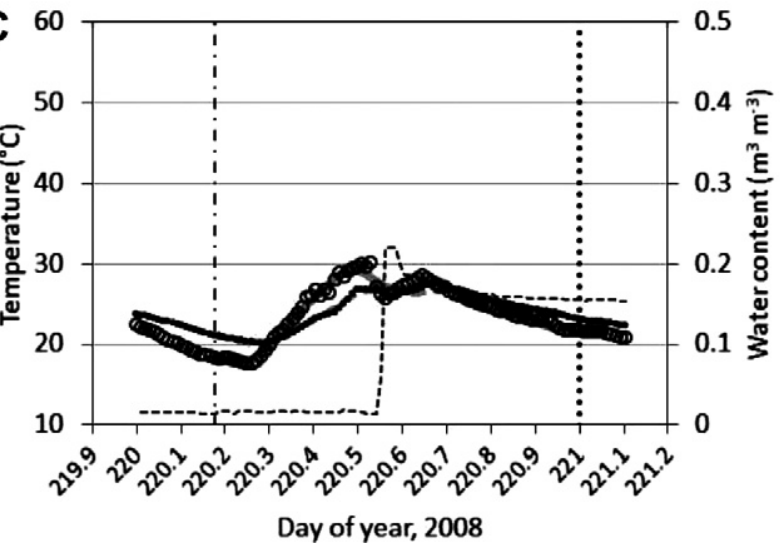

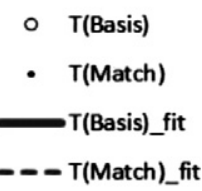

Location: 1

Basis depth $(\mathrm{cm}): 0$

Matching depth $(\mathrm{cm}): 4$

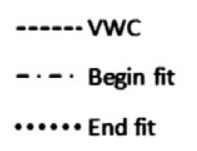

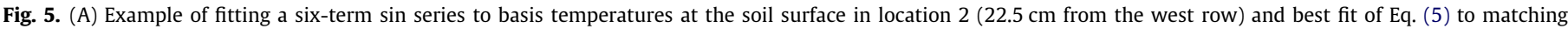

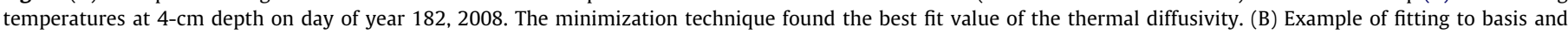

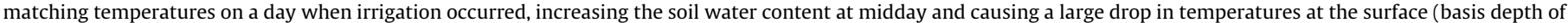

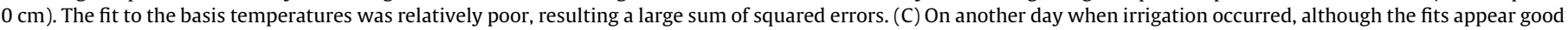
the thermal diffusivity value is optimized across a wide range of water contents, making conversion to thermal conductivity impractical. 


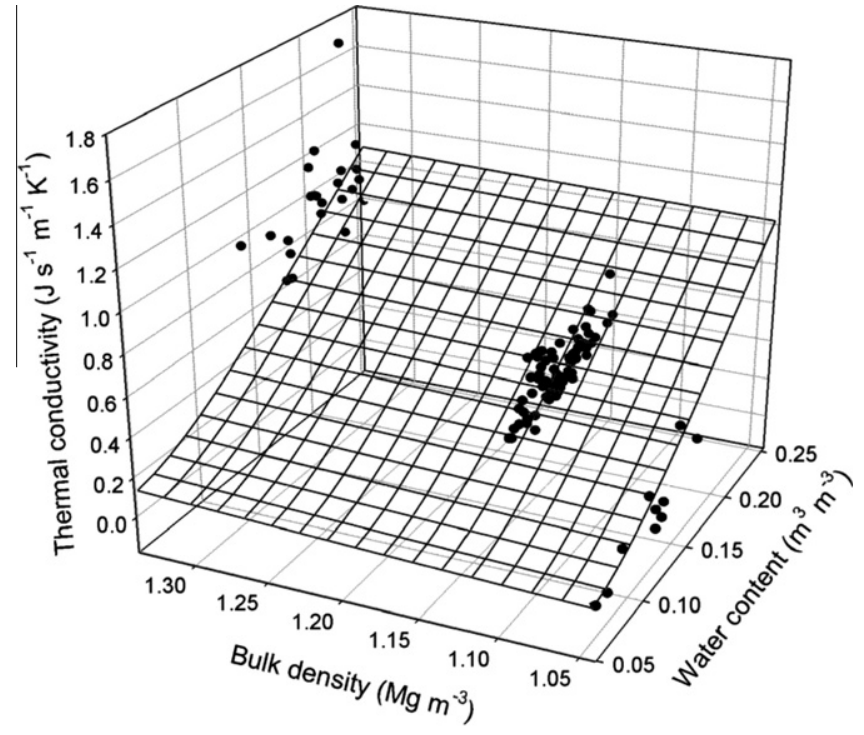

Fig. 6. Three-dimensional plot of soil water content, bulk density and thermal conductivity data with fitted model (Eq. (15)) surface.

the interrow were the last to warm as the changing sun angle caused first the western side of the interrow then the eastern side to be illuminated. This pattern was also observed at 4- and 8-cm depths, albeit with lag time increasing with depth and with less distinction. At the $16-\mathrm{cm}$ depth, locational $T$ differences were mostly damped out. Irrigation and precipitation events caused depression of all surface and subsurface temperatures (Fig. 4(c)) since both precipitation and the well water used for irrigation were typically cooler than soil temperatures in the summer.

\subsection{Finding $\alpha$ and $\kappa\left(\theta, \rho_{b}\right)$}

An example of well fitted basis temperatures, matching temperatures, the fitted Fourier series and the fitted matching temperatures is shown in Fig. 5(a). For this example, the initial water content was 0.165 , the final water content was 0.147 , and the fitted thermal conductivity was $0.239 \mathrm{~J} \mathrm{~s}^{-1} \mathrm{~m}^{-1} \mathrm{~K}^{-1}$. The phase difference (PD) was $0.095 \mathrm{~d}$, so the diffusivity was fit (nonlinear regression) to data starting at PD $+2 / 24=0.178 \mathrm{~d}$ and ending at $1.012 \mathrm{~d}$ as shown by the beginning and ending of the fitted lines in Fig. 5(a). On most irrigation days, surface temperature dropped so quickly and so much that the Fourier series fit to basis temperatures at the soil surface was not good, as illustrated for DOY 199 (Fig. 5(b)); and the resulting large sum of squared errors eliminated the $\alpha$ data from further consideration. Good fitting of the basis and matching temperatures did not, however, always result in a useful estimate of thermal diffusivity as illustrated in Fig. 5(c) for DOY 220 when irrigation occurred. Although fits to temperature data appeared good, the $\alpha$ value was associated with a wide range of water contents and it was not reasonable to convert the fitted value to a thermal conductivity value.

Eq. (15) was fit with an adjusted $r^{2}=0.52$ and standard error (SE) of $\kappa$ estimate of $0.18 \mathrm{~J} \mathrm{~s}^{-1} \mathrm{~m}^{-1} \mathrm{~K}^{-1}$ over a range in $\theta$ of 0.05

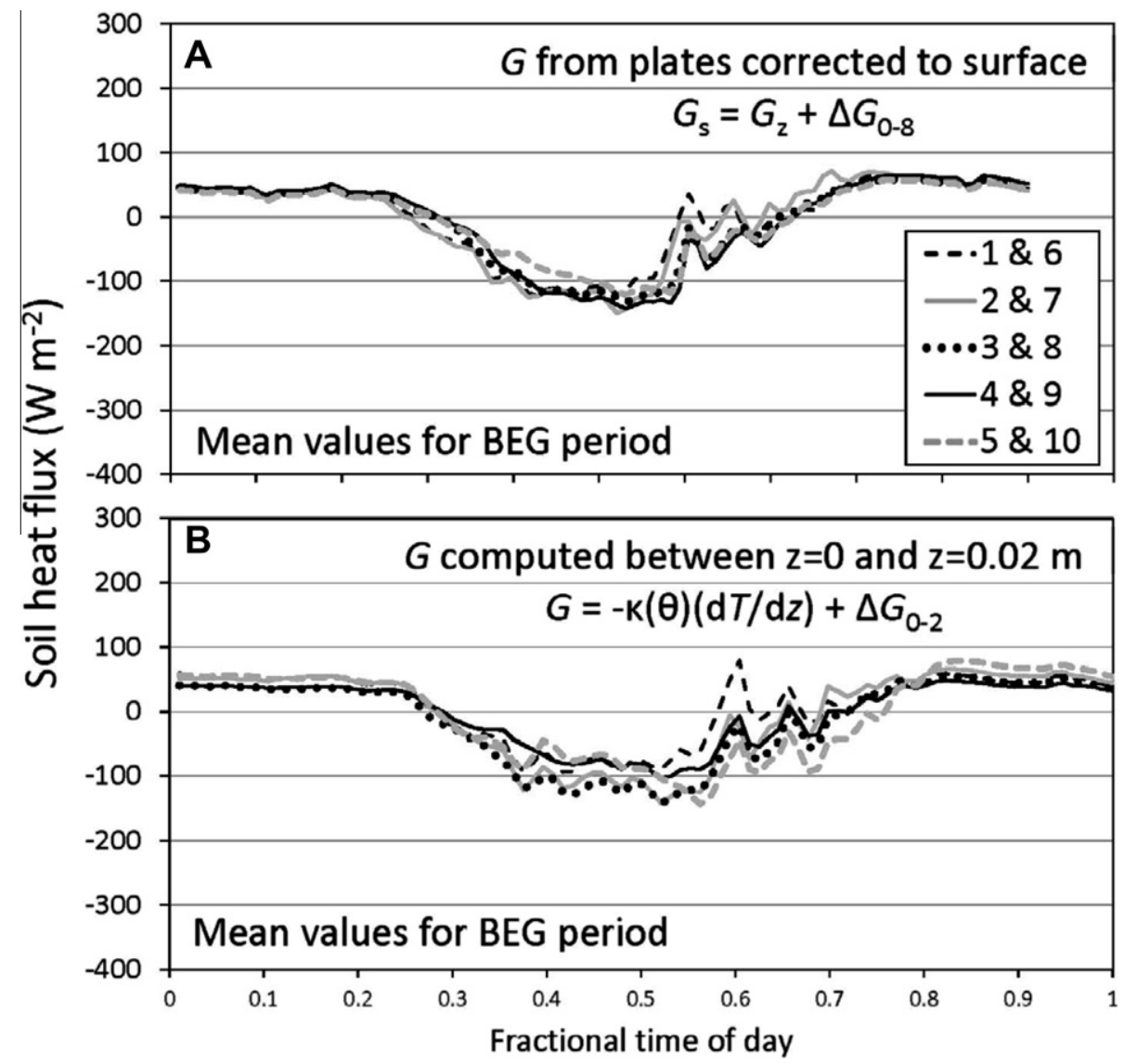

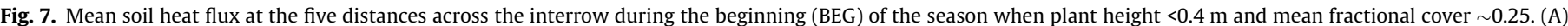

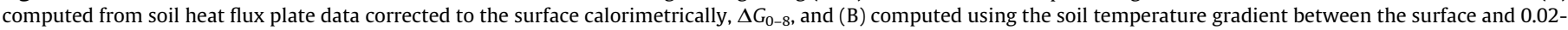
$\mathrm{m}$ depth and adjusted for flux divergence, $\Delta G_{0-2}$, within that layer. The numbers in the legend correspond to the locations as shown in Fig. 1 . 

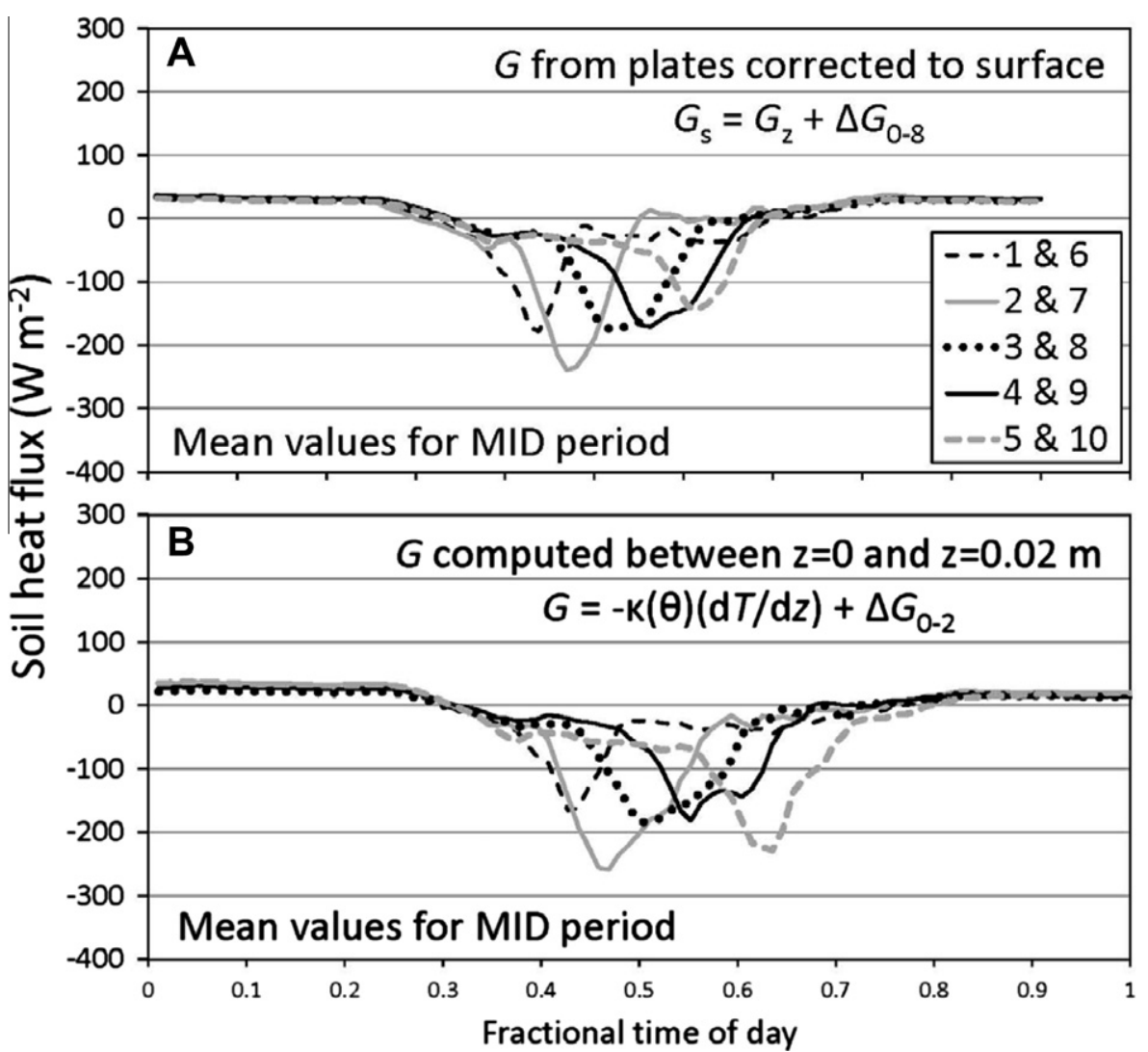

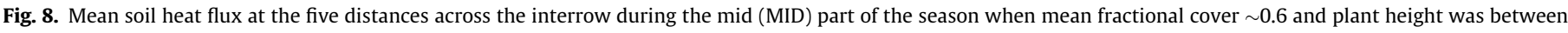

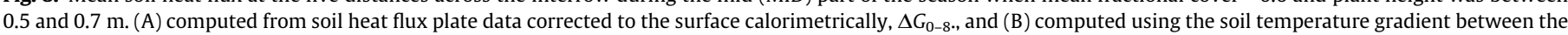
surface and $0.02-\mathrm{m}$ depth and adjusted for the flux divergence, $\Delta G_{0-2}$, within that layer. The numbers in the legend correspond to the locations as shown in Fig. 1 .

to $0.22 \mathrm{~m}^{3} \mathrm{~m}^{-3}$ and range in $\rho_{b}$ of 1.04 to $1.34 \mathrm{Mg} \mathrm{m}^{-3}$ (Fig. 6). These results were not as precise as those found by Evett [8] in bare soil for which the diel temperature wave at the surface was more sinusoidal in shape due to the absence of vegetation $\left(r^{2}=0.84, \mathrm{SE}=0.10 \mathrm{~J} \mathrm{~s}^{-1} \mathrm{~m}^{-1} \mathrm{~K}^{-1}\right)$. Examination of Fig. 6 indicates that bulk density had a weak positive effect on $\kappa$ but water content had a strong positive effect on $\kappa$. There was also more scatter in the data at the largest bulk density, which was for the 8-cm basis and 16-cm matching depths. Diel amplitudes at these depths were much damped compared to shallow depths, resulting in relatively inexact determination of $\alpha$ and $\kappa$.

\subsection{Determining $G_{0}$}

Magnitudes of period-mean diel $G_{0}$ were largest during the BEG period, peaking at $-150 \mathrm{~W} \mathrm{~m}^{-2}$ for $G_{\mathrm{PS}}$ and $-143 \mathrm{~W} \mathrm{~m}^{-2}$ for $G_{\text {grad }}$ (Fig. 7). Dynamics of $G_{0}$ were similar for the two methods, though $G_{\text {grad }}$ was somewhat more variable between measurement positions. Neither method showed a strong influence of position within the interrow during this period when $f_{c}<0.3$ and $h_{c},<0.4 \mathrm{~m}$. During the MID period, shading of the interrow caused strong spatiotemporal variations in $G_{0}$ (Fig. 8), similar to those shown in [29]. Soil heat flux was largest on the western side of the interrow in the morning hours, largest in the middle of the interrow near noon and largest on the eastern side of the interrow in the afternoon due to the sunlit portion of the interrow changing from the western to the eastern side over the course of the daytime hours. Maximum absolute $G_{0}$ values were somewhat larger for $G_{\text {grad, }}$, and diel patterns showed more temporal variation, likely due to the use of surface $T$ in the calculation of divergence. During the END period, $G_{0}$ values showed peaks for only the middle three positions (Fig. 9). Peak values were much diminished due to the almost complete shading of the interrow. Values returned to near zero much more quickly after a peak for $G_{\text {grad }}$ than for $G_{\mathrm{PS}}$, likely also due to the inclusion of surface temperature in the divergence calculation. The observed diel spatio-temporal variation in $G_{0}$ parallels that observed for evaporation, $E$, from the soil surface as measured using microlysimeters by Agam et al. 2012 [17]. As with $G_{0}$, soil $E$ peaked earlier in the day on the west side of the interrow and peaked later in the day on the east side of the interrow for $\mathrm{N}-\mathrm{S}$ row orientation.

These patterns and the conclusions drawn from them are practically identical to those reported by Agam et al. 2012 [24], indicating that the gradient flux and heat flux plate methods are capable of identifying spatiotemporal variations in $G_{0}$ accurately. Despite the similar dynamics, however, the 24-h and daytime sums of heat flux were different for $G_{\mathrm{PS}}$ and $G_{\text {grad }}$ (Table 1). Daytime sums of $G_{\mathrm{PS}}$ ranged from between -3.0 and $-3.9 \mathrm{MJ} \mathrm{m}^{-2}$ during the BEG period to near -1 during the END period with only modest variation by position. Daytime sums of $G_{\text {grad }}$, in contrast, were much more variable by position, ranging from -1.7 to $-4.3 \mathrm{MJ} \mathrm{m}^{-2}$ for the BEG period, from -2.6 to $-4.9 \mathrm{MJ} \mathrm{m}^{-2}$ during the MID period, and ranging from 0.1 to $-1.2 \mathrm{MJ} \mathrm{m}^{-2}$ during the END period. The less negative and even positive values of $G_{\text {grad }}$ during the END period, when compared to those for $G_{\mathrm{PS}}$, may be more accurate, indicating that the soil was warming only a little or even beginning to cool (positive $G_{0}$ ) during this end-of-season period (DOY 239-254, 26 August to 10 September). Sums over $24 \mathrm{~h}$ indicated even more soil cooling early and late in the season when gradient flux values are considered as compared with heat flux plate data. The generally larger magnitudes of daytime sums of heat flux compared with 24-h sums indicate the importance of considering soil heat flux 


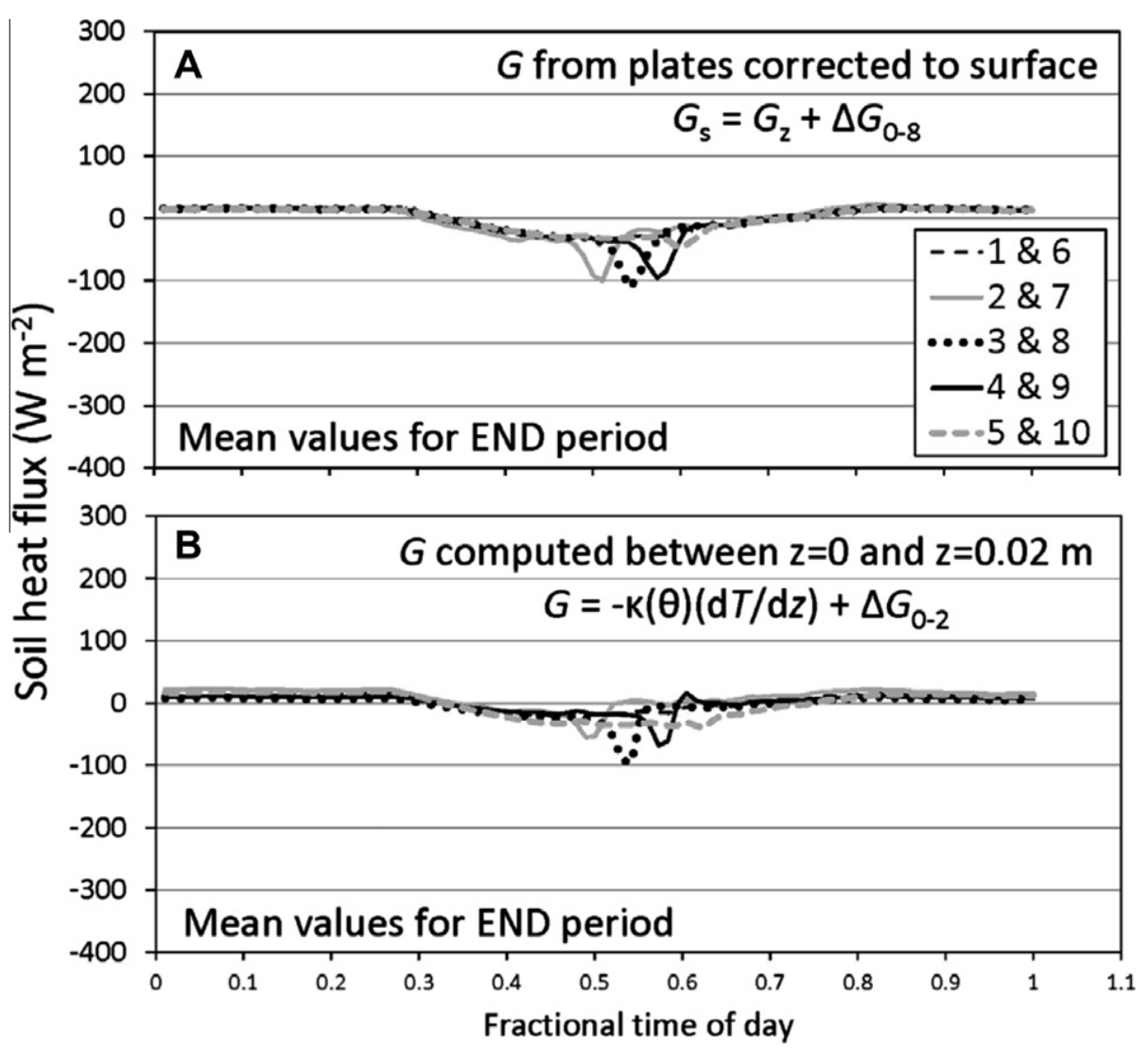

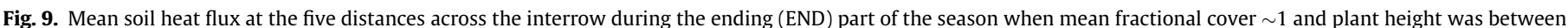

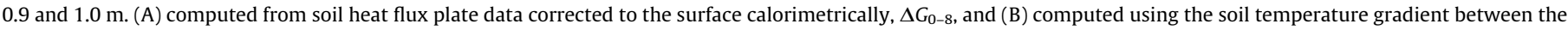
surface and $0.02-\mathrm{m}$ depth and adjusted for flux divergence, $\Delta G_{0-2}$, within that layer. The numbers in the legend correspond to the locations as shown in Fig. 1.

Table 1

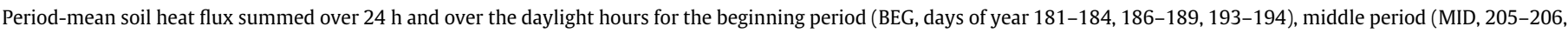

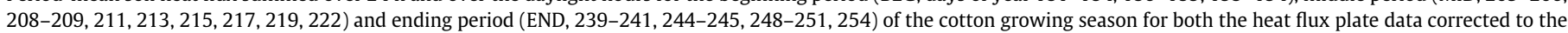

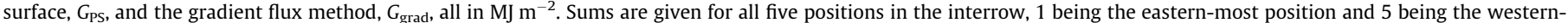
most position.

\begin{tabular}{|c|c|c|c|c|c|c|c|c|c|c|}
\hline & $\begin{array}{l}\text { Positio } \\
1\end{array}$ & 2 & 3 & 4 & 5 & 1 & 2 & 3 & 4 & 5 \\
\hline Period & \multicolumn{5}{|c|}{ 24-h sum } & $\begin{array}{l}\text { Daytim } \\
G_{\mathrm{PS}}(\mathrm{M}\end{array}$ & \multicolumn{3}{|c|}{ Daytime sum } & \\
\hline BEG & -0.19 & -0.42 & -0.52 & -0.56 & -0.36 & -3.02 & -3.28 & -3.57 & -3.88 & -3.11 \\
\hline MID & -0.24 & -0.44 & -0.44 & -0.39 & -0.21 & -2.15 & -2.53 & -2.51 & -2.59 & -2.03 \\
\hline \multirow[t]{2}{*}{ END } & -0.02 & -0.10 & -0.13 & -0.13 & -0.05 & -0.92 & -1.10 & -1.12 & -1.15 & -0.93 \\
\hline & \multicolumn{5}{|c|}{$G_{\text {grad }}\left(\mathrm{MJ} \mathrm{m}^{-2}\right)$} & \multicolumn{5}{|c|}{$G_{\text {grad }}\left(\mathrm{MJ} \mathrm{m}^{-2}\right)$} \\
\hline BEG & 0.71 & -0.10 & -1.17 & -0.18 & -0.27 & -1.71 & -3.29 & -4.33 & -2.57 & -3.94 \\
\hline MID & -0.77 & -1.65 & -1.48 & -1.01 & -1.95 & -2.58 & -4.47 & -3.60 & -3.00 & -4.86 \\
\hline END & 0.37 & 0.76 & -0.27 & 0.04 & -0.16 & -0.26 & 0.14 & -0.89 & -0.47 & -1.17 \\
\hline
\end{tabular}

as part of the energy balance on time scales less than a day. Even breaking these data down into daytime and nighttime sums show the considerable impact that soil heat flux has on the overall energy available to drive evaporation during the day. When considered on an hourly or shorter time interval, the impact of soil heat flux on available energy is even more evident.

\subsection{Comparing $G_{0}$ to $E$}

Evaporation (E) from the soil surface was measured using microlysimeters [17] and data are shown in Table 2 for the period when both $G_{0}$ and $E$ data were available (DOY 198-215). This was mostly during the MID period. Comparison of period-total $G_{\text {grad }}$ with period-total $E\left(\mathrm{MJ} \mathrm{m}^{-2}\right)$ showed that soil heat flux was positive (towards the surface) during all nighttime periods, as would be expected, and negative (away from the surface) during all daytime periods (Fig. 10). The 24 -h total $G_{\text {grad }}$ values were also all negative, also expected since the measurements occurred from 25 June to 2 August 2008 when the soil was still warming. There were weak negative correlations between $G_{0}$ and $E,\left(r^{2}=0.27\right.$ for 24-h and 0.20 for daytime) indicative that most of the energy driving both was from net radiation (sensible heat flux being limited by the mostly closed canopy). The positive $G_{\text {grad }}$ at night probably contributed to the small nighttime $E$ flux.

The data from soil heat flux plates corrected to the surface $\left(G_{\mathrm{PS}}\right)$ were less easily explained. The $24-\mathrm{h} G_{\mathrm{PS}}$ sum was positive on three days (DOY 201, 213 and 215). DOY 201 was partly cloudy, but alfalfa reference ET [27,28] was still $5.9 \mathrm{~mm}$ [17]. On DOYs 213 and 215 , alfalfa reference ET was 7.1 and $8.3 \mathrm{~mm}$, respectively, due to the relatively clear skies and strong solar irradiance. It is 

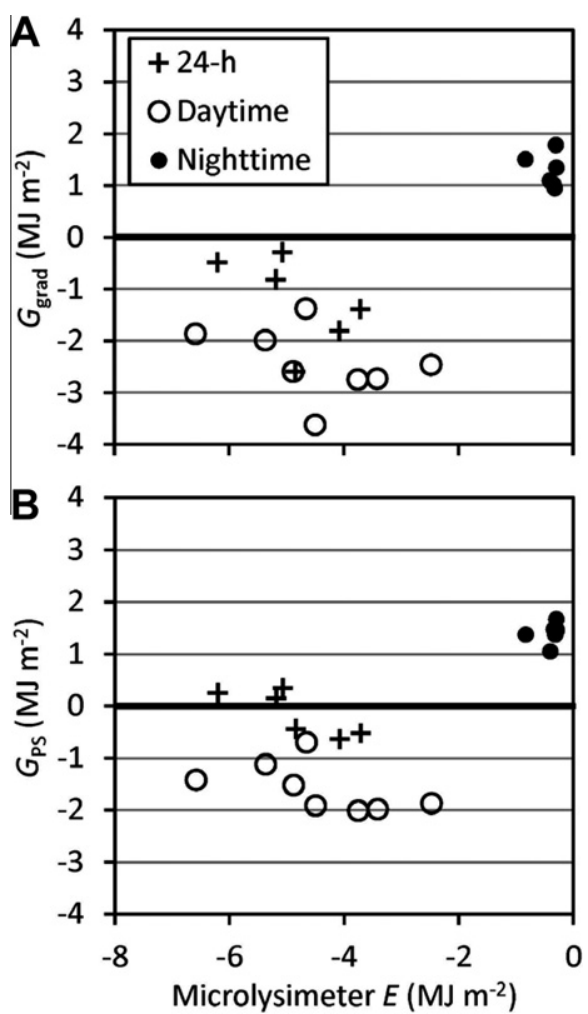

Fig. 10. Soil surface heat flux ( $\left.\mathrm{MJ} \mathrm{m}^{-2}\right)$ as calculated using the gradient method, $G_{\text {grad }}(\mathrm{A})$, and using plate data and calorimetric correction, $G_{\mathrm{PS}}(\mathrm{B})$, for 24-h, daytime and nighttime periods when evaporation $(E)$ from the soil surface $\left(\mathrm{MJ} \mathrm{m}^{-2}\right.$ ) was measured using microlysimeters.

not reasonable to expect positive $G_{0}$ on days with strong solar irradiance and for which $E$ was not larger than on other days with negative $G_{P S}$ (Table 2). And, soil temperature data indicated that the soil was not cooling during the DOY 198-215 period as would be required if daily mean $G_{0}$ were positive (towards the surface).

\subsection{Spatial variation of $G$}

A subset of data was examined for the period from DOY 198215 when crop height $(0.3-0.4 \mathrm{~m})$ and leaf area index (0.4-1.7) were great enough to cause spatiotemporal variation in sunlit soil areas in the interrow of the N-S rows. Soil heat flux varied four to six times more across the interrow when determined using the flux gradient method $\left(G_{\text {grad }}\right)$ compared with heat flux determined using plates and calorimetric correction to the surface ( $G_{\mathrm{PS}}$, Table 3 ).
Table 3

Standard deviations (SD) across the five interrow positions of soil heat flux as determined using plates buried at $0.08-\mathrm{m}$ depth $\left(G_{8}\right)$, the divergence of heat flux $\left(\Delta G_{08}\right)$ in the soil above the plates, the heat flux from the plates corrected to the surface $\left(G_{\mathrm{PS}}\right)$ and the heat flux as calculated using the flux gradient method $\left(G_{\text {grad }}\right)$, for six days of year (DOY) in 2008 for both 24 -h periods and daytime periods. Standard deviation was calculated on the mean of two replicate systems at each interrow position.

\begin{tabular}{|c|c|c|c|c|c|c|c|c|}
\hline \multirow[t]{3}{*}{ DOY } & \multicolumn{4}{|c|}{ 24-h standard deviation } & \multicolumn{4}{|c|}{ Daytime SD } \\
\hline & \multicolumn{8}{|c|}{$\mathrm{MJ} \mathrm{m} \mathrm{m}^{-2}$} \\
\hline & $G_{8}$ & $\Delta G_{0 \_8}$ & $G_{\mathrm{PS}}$ & $G_{\text {grad }}$ & $G_{8}$ & $\Delta G_{0 \_8}$ & $G_{\mathrm{PS}}$ & $G_{\text {grad }}$ \\
\hline 198 & 0.03 & 0.02 & 0.03 & 0.76 & 0.10 & 0.03 & 0.11 & 0.96 \\
\hline 200 & 0.20 & 0.05 & 0.25 & 0.80 & 0.24 & 0.12 & 0.35 & 0.80 \\
\hline 201 & 0.08 & 0.03 & 0.08 & 0.87 & 0.11 & 0.05 & 0.15 & 0.92 \\
\hline 202 & 0.07 & 0.02 & 0.09 & 0.96 & 0.15 & 0.02 & 0.17 & 1.42 \\
\hline 205 & 0.10 & 0.02 & 0.11 & 0.94 & 0.15 & 0.03 & 0.17 & 1.19 \\
\hline 213 & 0.13 & 0.03 & 0.16 & 0.41 & 0.16 & 0.09 & 0.23 & 0.58 \\
\hline 215 & 0.11 & 0.03 & 0.14 & 0.39 & 0.14 & 0.07 & 0.21 & 0.41 \\
\hline
\end{tabular}

Values of $G_{\text {grad }}$ were typically more negative than $G_{\mathrm{PS}}$ values (Fig. 11), although not universally. There was some persistence in the spatial pattern of $G_{\text {grad }}$ with positions 1 and 4 often exhibiting less negative values than other positions. This was likely the result of microtopographic effects on surface ponding of water and the resulting persistence of wetter and cooler spots across the interrow. The gradient flux method was responsive to this micro-variability and likely rendered more accurately the true variability of surface heat flux than did data from heat flux plates corrected to the surface. Not only is the gradient flux method more responsive to surface temperature and temperature gradient variation across the interrow, but it does not suffer as much from lateral divergence of heat from one position to the next as does the plate method. The necessary assumption for correcting heat flux plate data to the surface is that heat flux is one-dimensional and vertical. In an environment where sun-lit areas of the interrow are changing over the day and as wind moves the canopy, however, heat flux is very likely strongly three-dimensional. Ham and Kluitenberg [29] showed that heat flux plate measurements (corrected for heat storage in the layer between soil surface and the plates) were subject to large errors (up to $50 \mathrm{~W} \mathrm{~m}^{-2}$ ) in a row crop environment as a result of horizontal temperature gradients. They also showed that "the use of spatially averaged parameters to describe soil processes beneath partial canopies may have little physical meaning in regard to certain parameters or processes." Lateral divergence of heat tends to distribute heat across the interrow, reducing the variation of heat flux calculated using the calorimetric correction method and making heat flux appear to be less spatially variable than it actually is. Because of this, one probably should use more replicate measurements when using the flux gradient method in order to get

Table 2

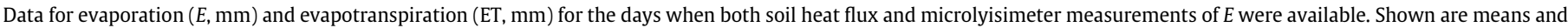

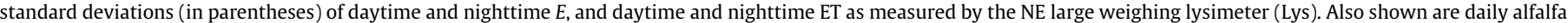

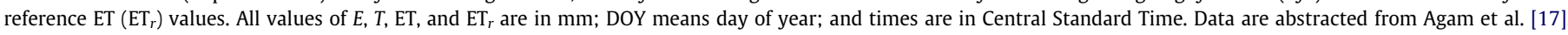

\begin{tabular}{|c|c|c|c|c|c|c|}
\hline Date (2008) & DOY & Day-time $E$ & Night-time $E$ & Day-time Lys ET & Night-time Lys ET & $\mathrm{ET}_{r}$ \\
\hline & & $\mathrm{mm}$ & & & & \\
\hline $7 / 16$ & 198 & $1.40(0.09)$ & $0.12(0.03)$ & 5.61 & 0.38 & 5.82 \\
\hline $7 / 18$ & 200 & $2.69(0.80)$ & & 6.81 & & 7.35 \\
\hline $7 / 19$ & 201 & $1.90(0.39)$ & $0.17(0.03)$ & 6.44 & 0.45 & 5.94 \\
\hline $7 / 20$ & 202 & $1.53(0.26)$ & $0.13(0.05)$ & 7.52 & 0.46 & 8.40 \\
\hline \multicolumn{7}{|c|}{$7 / 22 / 2008$ - irrigation } \\
\hline $7 / 23$ & 205 & $1.84(0.15)$ & $0.14(0.03)$ & 8.77 & 0.51 & 7.59 \\
\hline $7 / 24$ & 206 & $1.01(0.07)$ & $0.00(0.03)$ & 7.67 & 0.38 & 8.35 \\
\hline \multicolumn{7}{|c|}{$7 / 28 / 2008$ and $7 / 30 / 2008$ - irrigation } \\
\hline $7 / 31$ & 213 & $1.99(0.20)$ & $0.12(0.06)$ & 9.88 & 0.38 & 7.07 \\
\hline $8 / 2$ & 215 & $2.19(0.19)$ & $0.34(0.08)$ & 10.59 & 0.92 & 8.28 \\
\hline
\end{tabular}




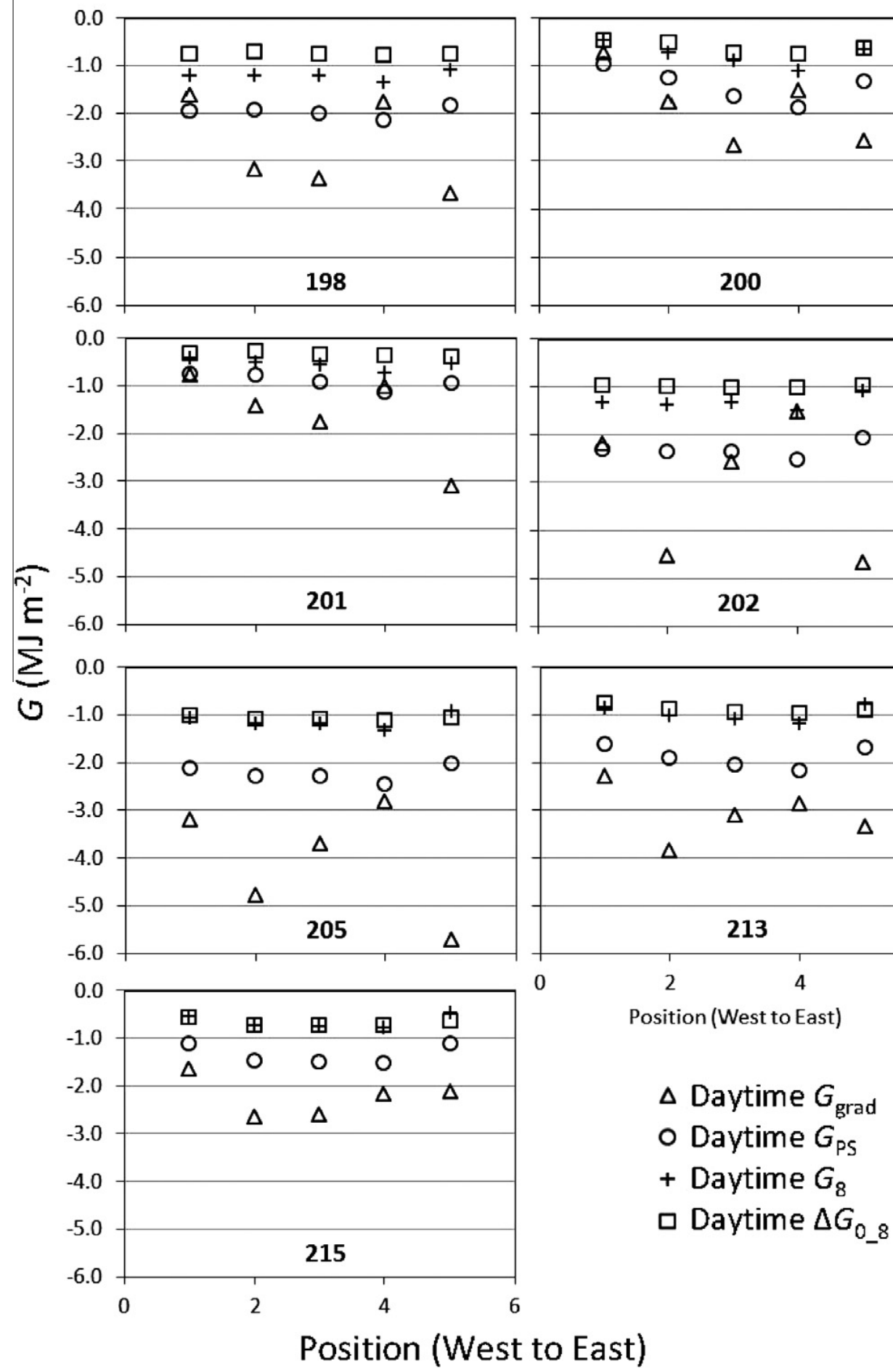

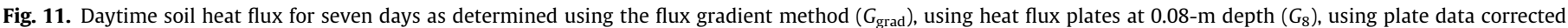
calorimetrically to the surface $\left(G_{\mathrm{PS}}\right)$, and the calorimetric correction itself $\left(\Delta G_{0_{-} 8}\right)$.

a mean value close to the true mean. On the other hand, although the standard deviation of surface heat flux calculated from plate data was smaller and fewer replicates would thus be required to achieve the same precision, this approach avails nothing if the heat flux data are inaccurate, as is suggested by the discussion in Sections 3.2 and 3.3. On the other hand, using the surface temperature in the thermometric correction to heat flux plate data may improve the accuracy, a thought that we will explore in a subsequent paper.

\section{Summary}

In summary, we presented a field method for determining the relationship between soil thermal conductivity, water content and bulk density, a relationship heretofore usually determined in the laboratory or estimated from theory. The method combines determination of soil water content, using TDR, and soil temperature, using thermocouples, to gather a data set that is then analyzed using analytical and statistical methods to determine 
the apparent thermal conductivity, $\kappa$, for a particular day and soil layer. The $\kappa$ values for all layers and days were then related to the daily mean water contents of the corresponding layers and days and the layer bulk density values by fitting to a $\kappa\left(\theta, \rho_{b}\right)$ model. Similar to results of Evett [8], the bulk density effect was minor and could have been ignored with small loss in accuracy. Results are promising in that they relate well to previous work and allow better simulation of soil surface heat flux, $G_{0}$, using a mechanistic model [16]. The $\kappa\left(\theta, \rho_{b}\right)$ function was used in a flux gradient calculation of $G_{0}$ using surface and 2-cm deep measurements of soil temperature plus water content measurements to determine the volumetric heat capacity in the $0-2-\mathrm{cm}$ layer. The flux gradient method better represented the surface spatiotemporal variation in heat flux than did measurements using plates buried at 0.08 $m$ depth and corrected to the surface calorimetrically. The flux gradient method was also more accurate than the heat flux plate method in that it reflected continued soil warming, congruent with soil temperature data, while heat flux plate data sometimes indicated soil cooling. The advent of soil water sensors capable of accurately and inexpensively sensing water content and temperature in thin layers near the soil surface [25] will allow the method presented to be used routinely for joint determinations of near-surface soil water content and temperature dynamics, the soil-specific $\kappa\left(\theta, \rho_{b}\right)$ function, and surface and subsurface soil heat fluxes.

\section{Acknowledgement}

This research was supported in part by the Ogallala Aquifer Program, a consortium between USDA-Agricultural Research Service, Kansas State University, Texas AgriLife Research, Texas AgriLife Extension Service, Texas Tech University, and West Texas A\&M University.

\section{References}

[1] De Vries DA. Thermal properties of soils. In: van Wijk WR, editor. Physics of plant environment. Amsterdam: North-Holland Publishing Co.; 1964. p. 210-35.

[2] Horton R, Wierenga PJ, Nielsen DR. Evaluation of methods for determining the apparent thermal diffusivity of soil near the surface. Soil Sci Soc Am J 1983;47:25-32.

[3] Costello TA, Braud Jr HJ. Thermal diffusivity of soil by nonlinear regression analysis of soil temperature data. Trans ASAE 1989;32(4):1281-6.

[4] Nassar IN, Horton R. Determination of the apparent thermal diffusivity of a nonuniform soil. Soil Sci 1989;147(4):238-44.

[5] Nassar IN, Horton R. Determination of soil apparent thermal diffusivity from multiharmonic temperature analysis for nonuniform soils. Soil Sci 1990;149(3):125-30.

[6] Alsanabani MM. Soil water determination by time domain reflectometry: Sampling domain and geometry, Ph.D. thesis, Department of Soil and Water Sciences, Univ. of Arizona, Tucson, 1991.

[7] Baker JM, Lascano RJ. The spatial sensitivity of time-domain reflectometry. Soil Sci 1989;147:378-84.
[8] Evett SR. TDR-Temperature arrays for analysis of field soil thermal properties. in: Proc. Symp. on TDR in Environment Infrastructure and Mining Application, Northwestern Univ., Evanston, IL, 1994, pp. 320-327.

[9] Ren T, Ochsner TE, Horton R. Development of thermo-time domain reflectometry for vadose zone measurements. Vadose Zone J 2003;2:544-51.

[10] Sauer TJ, Horton R. Soil heat flux. In: Hatfield JL, Baker JM, editors. Micrometeorology in agricultural systems. Agron Monogr, 47. Am Soc of Agron Madison, WI; 2005. p. 131-54.

[11] Yang K, Wang JM. A temperature prediction-correction method for estimating surface soil heat flux from soil temperature and moisture data. Sci China Ser DEarth Sci 2008;51(4):1-9.

[12] Evett SR, Prueger JH, Tolk JA. Water and energy balances in the soil-plantatmosphere continuum. In: Huang PM, Li Y, Sumner ME, editors. Handbook of soil sciences: Properties and processes, 2nd ed. Boca Raton, Florida, USA: CRC Press; 2011. p. 6-1-44. ISBN 978-1-4398-0305-9.

[13] Heitman JL, Horton R, Sauer TJ, Ren TS, Xiao X. Latent heat in soil heat flux measurements. Agric Forest Meteorol 2010;150:1147-53.

[14] Sprott JC. Numerical recipes routines and examples in BASIC. Cambridge UK: Cambridge University Press; 1991.

[15] Campbell GS. Soil physics with BASIC. New York: Elsevier; 1985.

[16] Evett SR, Howell TA, Schneider AD, Copeland KS, Dusek DA. Energy and water balance modeling of winter wheat. Amer. Soc. Agric. Engr., Paper No. 942022, ASAE, 2950 Niles Rd., St. Joseph, MI 49085-9639. 1994.

[17] Agam N, Evett JA, Tolk WP, Kustas PD, Colaizzi JG, Alfieri LG, McKee KS, Copeland TA. Howell, Chávez JL. Evaporative loss from irrigated interrows in a highly advective semi-arid agricultural area. Adv Water Resour 2012;50:20-30.

[18] Evett SR, Kustas WP, Gowda PH, Howell TA. Overview of the Bushland Evapotranspiration (ET) and Agricultural Remote sensing EXperiment 2008 (BEAREX08): a field experiment evaluating techniques quantifying ET at multiple scales. Adv Water Resour 2012;50:4-19.

[19] Evett SR. The TACQ program for automatic time domain reflectometry measurements: I. Design and operating characteristics. Trans ASAE 2000; 43(6):1939-46.

[20] Evett SR. The TACQ program for automatic time domain reflectometry measurements: II. Waveform interpretation methods. Trans ASAE 2000; 43(6):1947-56.

[21] Evett SR. Coaxial multiplexer for time domain reflectometry measurement of soil water content and bulk electrical conductivity. Trans ASAE 1998; 41(2):361-9.

[22] Zegelin SJ, White I, Jenkins DR. Improved field probes for soil water content and electrical conductivity measurement using time domain reflectometry. Water Resour Res 1989;25(11):2367-76.

[23] Evett SR, Tolk JA, Howell TA. TDR laboratory calibration in travel time, bulk electrical conductivity, and effective frequency. Vadose Zone J 2005;4:1020-9.

[24] Agam N, Kustas WP, Evett SR, Colaizzi PD, Cosh M, McKee LG. Soil heat flux variability influenced by row direction in irrigated cotton. Adv Water Resour 2012;50:31-40.

[25] Evett SR, Schwartz RC, Mazahreh N, Jitan M, Shaqir IM. Soil water sensors for irrigation scheduling: can they deliver a management allowed depletion? Acta Horticulturae 2011;888:231-7.

[26] Evett SR, Warrick AW, Matthias AD. Wall material and capping effects on microlysimeter temperatures and evaporation. Soil Sci Soc Am J 1995;59:329-36.

[27] Allen RG. 2002. REF-ET program. Version 2.01.17, dated 24 June 2002. Kimberly, Ida.: University of Idaho, Kimberly R\&E Center. Available at: www.kimberly.uidaho.edu/ref-et/. Accessed 11 August 2011. 2002.

[28] Allen RG, Walter IA, Elliott R, Howell T, Itenfisu D, Jensen M. The ASCE standardized reference evapotranspiration equation. Prepared by Task Committee on Standardization of Reference Evapotranspiration. Reston, Va.: ASCE Environmental and Water Resources Institute. Available at: www.kimberly.uidaho.edu/water/asceewri/ascestzdetmain.2005.pdf. 2005.

[29] Ham JM, Kluitenberg GJ. Positional variation in the soil energy balance beneath a row-crop canopy. Agric For Meteorol 1993;63:73-92. 